\title{
KAJIAN LAPANG PENGGUNAAN BENIH NILA (O. niloticus) HASIL PEMULIAAN DI KERAMBA JARING APUNG JATILUHUR
}

\author{
Estu Nugroho"), Saepudin ${ }^{* *}$, dan Mochamad Bajar ${ }^{* * *}$ \\ ") Pusat Penelitian dan Pengembangan Perikanan Budidaya \\ Jl. Ragunan 20, Pasar Minggu, Jakarta Selatan 12540 \\ E-mail: engroho@yahoo.com \\ *) Pembudidaya KJA Cirata \\ ***) Pembenih Ikan Nila, Cianjur \\ Jl. Ds. Cinangsi, Tarikolot, Cikalong Kulon
}

(Naskah diterima: 12 Juni 2012; Disetujui publikasi: 4 Februari 2013)

\begin{abstract}
ABSTRAK
Penelitian penggunaan benih nila hasil pemuliaan dalam skala usaha telah dilakukan dengan menggunakan keramba jaring apung (KJA) petani yang ada di daerah Waduk Jatiluhur (Ir. H. Djuanda) Jawa Barat. Dua perlakuan yang digunakan yaitu: benih nila hasil pemuliaan dan benih lokal sebagai kontrol, masing-masing dengan empat ulangan yang dipelihara pada KJA dengan volume $1.800 \mathrm{~m}^{3}$. Parameter yang diamati meliputi sintasan, pertambahan bobot total harian, produksi saat panen dan nilai ekonomisnya. Hasil yang diperoleh menunjukkan bahwa benih hasil pemuliaan mempunyai produktivitas lebih baik dibandingkan benih nila lokal. Nilai rata-rata yang dimiliki oleh benih nila unggul adalah $70,74 \%$ (sintasan); $7,22 \mathrm{~kg} /$ hari (pertambahan bobot total harian); 1.274,5 kg (total panen); dan Rp 7.305.000,- (laba/periode). Sementara benih nila lokal mempunyai nilai rata-rata $57,28 \%$ (sintasan); $3,45 \mathrm{~kg} /$ hari (pertambahan bobot total harian); 620,5 kg (total panen); dan Rp 1.583.310,- (laba/periode).
\end{abstract}

KATA KUNCI: kajian lapang, nila unggul, KJA Jatiluhur

ABSTRACT: On farm research of a good quality tilapia seed in net cagesJatiluhur. By: Estu Nugroho, Saepudin, and Mochamad Bajar

On farm research of using selection activity result of tilapia seeds has been conducted in farmer's net cages located in Jatiluhur-West Java (Ir. H. Djuanda) Reservoir. Two treatments are applied in this research i.e. culturing a selection seeds and local stocks as a control in net cages with total volume 1,800 $\mathrm{m}^{3}$; each has four replications. Parameters observed including survival rate, addition of total biomass/day, total harvest and their economic value. The result was shown that a selection of seed has average value on productivity better than the local seed ones. The average values of a selection seed i.e. $70.74 \%$ (survival rate); $7.22 \mathrm{~kg} /$ day (addition of total biomass/ day), $1,274.5 \mathrm{~kg}$ (total harvest); and $R p 7,350,000$,- (benefit/period). While local seed has the average value of $57.28 \%$ (survival rate); $3.45 \mathrm{~kg} /$ day (addition of total biomass/ day); $620.5 \mathrm{~kg}$ (total harvest); and Rp 1,583,310,-(benefit/period).

KEYWORDS: field study, good quality tilapia, Jatiluhur net cages 


\section{PENDAHULUAN}

Perikanan budidaya ikan nila (O. niloticus) sebagai salah satu kegiatan agribisnis mulai berkembang sejak tahun 1990-an. Salah satu sentra kegiatan agribisnis ikan nila adalah daerah Jawa Barat, khususnya di perairan Waduk Cirata dan Waduk Ir. H. Djuanda, Jatiluhur. Dewasa ini tercatat hampir sekitar 4.000 ton pakan dibutuhkan untuk budidaya ikan di Waduk Jatiluhur (Komunikasi pribadi dengan distributor pakan).

Jika diasumsikan produksi ikan nila adalah setengah dari produksi ikan mas maka produk ikan nila yang dihasilkan dari KJA Jatiluhur mencapai sekitar 1.000 ton untuk setiap bulannya, dan jika dinilai dalam rupiah merupakan jumlah yang cukup besar, dengan harga ikan nila saat ini Rp 9.500,-/kg belum termasuk nilai hasil perbenihannya diperoleh angka Rp 9,5 miliar.

Keadaan ini telah banyak menarik minat para pemilik modal untuk melakukan bisnis budidaya, khususnya ikan nila yang dinilai mempunyai ketahanan terhadap perubahan lingkungan. Pemeliharaan ikan nila di Waduk Jatiluhur, umumnya dilakukan dengan sistem jaring ganda yaitu memelihara ikan nila di bawah jaring yang digunakan untuk memelihara ikan mas. Keadaan ini dilakukan untuk tujuan efisiensi pakan yang diberikan pada ikan mas. Pemeliharaan secara mandiri jarang dilakukan oleh petani mengingat harga pasar dan harga pokok produksi per satuan kilogramnya tidak seimbang (Nugroho, 2012a).

Keberhasilan pemeliharaan dengan sistem jaring ganda ini umumnya hanya menggantungkan pada faktor kualitas benih, mengingat faktor pakan yang mempunyai kontribusi hampir sekitar 60\%-70\% dari biaya produksi tidak menjadi faktor pembatas. Perbaikan kualitas benih ikan nila dilakukan dengan memproduksi induk-induk yang bermutu melalui berbagai program pemuliaan. Beberapa varietas unggul yang telah berhasil dilepas oleh para pemulia yang tergabung pada Pusat Induk Nila Nasional (kerja sama antara Badan Litbang Kelautan dan Perikanan dan UPT Dirjen Perikanan Budidaya) yang berpusat berada di Balai Besar Pengembangan Air Tawar Sukabumi di antaranya adalah nila Nirwana 1 dan 2 (Wanayasa), nila BEST (Bogor), nila GESIT (Sukabumi), nila Salin (Sukamandi), nila merah Larasati (Klaten), dan nila Jatibulan (Umbulan) (Nugroho, 2012b).
Penggunaan benih unggul ini merupakan salah satu pilar dari industrialisasi ikan nila yang sukses dilaksanakan oleh pemerintah Cina sejak tahun 1992, sehingga saat ini Cina dikenal sebagai negara produsen utama ikan nila. Tercatat produksi ikan nila di Cina telah mencapai sekitar 1,2 juta ton atau senilai US\$ 1,3 miliar pada tahun 2002 (Xinhua et al., 2011).

Kajian lapang penggunaan benih ikan nila hasil program pemuliaan dalam budidaya pada skala usaha dilakukan guna mendapatkan informasi pengaruh benih yang berkualitas unggul pada produksi budidaya ikan nila yang dipelihara pada jaring ganda di KJA yang berada di lokasi Waduk Ir. H. Djuanda, Jatiluhur-Jawa Barat.

\section{BAHAN DAN METODE}

Penelitian ini dilaksanakan di KJA milik pembudidaya di daerah Waduk Ir. H. Djuanda, Jatiluhur pada tahun 2011 . KJA yang digunakan untuk memelihara benih ikan nila mempunyai volume $1.800 \mathrm{~m}^{3}$.

Benih ikan nila yang digunakan dengan kisaran bobot 20-60 g/ekor merupakan hasil pemuliaan sebagai perlakuan dan benih ikan nila lokal yang banyak dipelihara di daerah Jatiluhur sebagai kontrol, masing-masing diulang sebanyak empat kali.

Kepadatan yang digunakan untuk setiap KJA mengacu pada bobot biomassa yaitu 300 $\mathrm{kg}$. Ikan dipelihara sampai mencapai ukuran konsumsi yaitu 125-200 g/ekor. Ikan nila mendapatkan pakan dari sisa pakan ikan mas yang dipelihara di jaring yang ada di atasnya, dengan cara pemeliharaan yang sama antara kedua perlakuan.

Parameter yang diamati meliputi sintasan, pertambahan bobot total per hari, produksi total, dan nilai ekonomis yang dilakukan pada akhir pemeliharaan. Data dianalisis menggunakan T-Test dengan program SSPS (Statistical Package for the Social Science) version 16 (Norman et al., 2010). Pengamatan secara total tanpa dilakukan sampling selama pemeliharaan ini dilakukan untuk mendekati semirip mungkin kegiatan usaha budidaya nila di KJA Jatiluhur secara bisnis.

\section{Sintasan}

Sintasan ikan yang dipelihara sampai ukuran konsumsi dihitung berdasarkan modifikasi dari persamaan Effendie (1979). Adapun persamaannya adalah sebagai berikut: 


$$
\mathrm{SR}=[(\mathrm{TP} / \mathrm{abi}-\mathrm{p}) /(\mathrm{TB} / \mathrm{abi}-\mathrm{t})] \times 100
$$

di mana:

$\mathrm{SR}=$ Sintasan (\%)

$\mathrm{TP}=$ Total panen $(\mathrm{kg})$

$\mathrm{TB}=$ Total biomassa saat tebar $(\mathrm{kg})$

abi-p = Rata-rata bobot individu saat panen $(\mathrm{kg})$

abi-t = Rata-rata bobot individu saat tebar $(\mathrm{kg})$

\section{Pertambahan Bobot Total Harian}

Pertambahan bobot total harian ikan nila sampai akhir penelitian dihitung berdasarkan modifikasi persamaan pertambahan bobot mutlak harian (National Research Council, 1983). Adapun persamaannya adalah sebagai berikut:

$$
\mathrm{PBTH}=(\mathrm{TP}-\mathrm{TB}) / \mathrm{t}
$$

di mana:

$\mathrm{PBTH}=$ Pertambahan bobot total harian $(\mathrm{kg} /$ hari)

$\mathrm{TP} \quad=$ Total panen $(\mathrm{kg})$

$\mathrm{TB}=$ Total biomassa saat tebar $(\mathrm{kg})$

$\mathrm{t}=$ Periode pemeliharaan (hari)

\section{Produksi Total (Panen Total)}

Produksi total atau panen total merupakan bobot biomassa total yang dihasilkan pada saat panen, diukur dalam satuan $\mathrm{kg} / \mathrm{KJA}$.

\section{Nilai Ekonomi}

Nilai ekonomi merupakan hasil perhitungan rugi laba yang dilakukan dengan hanya memasukkan unsur-unsur harga benih, penyusutan KJA, tenaga kerja, dan harga ikan konsumsi atau penjualan yang terjadi pada saat kegiatan dilakukan. Biaya produksi dihitung dengan standar harga benih, tenaga kerja, dan penyusutan yang sama, perbedaan hanya murni hasil dari jumlah produksi ikan yang diperoleh.

\section{HASIL DAN BAHASAN}

\section{Sintasan}

Secara statistik tidak terdapat perbedaan yang nyata pada sintasan benih unggul dan lokal $(P>0,05)$. Secara faktual, hasil pengamatan yang diperoleh menunjukkan bahwa benih hasil kegiatan pemuliaan mempunyai nilai sintasan yang lebih baik dibandingkan dengan benih ikan nila lokal yang umum digunakan oleh para pembudidaya di KJA Jatiluhur. Tercatat bahwa nila unggul mempunyai sintasan berkisar antara 63,18\%-84,11\% sedangkan benih ikan nila lokal mempunyai nilai sintasan antara 40,82\%-88,85\% (Tabel 1).

Nilai ini jauh lebih rendah jika dibandingkan pada pembesaran ikan nila dengan sistem mandiri yang telah diuji coba di Waduk Jatiluhur dan Cirata yang mempunyai nilai rata-rata untuk sintasan $86,77 \%$ (Jatiluhur) dan $80,48 \%$ (Cirata) (Nugroho, 2012a). Lebih rendahnya nilai sintasan dalam penelitian ini dapat dipahami mengingat ikan dipelihara secara jaring ganda sehingga hanya menggantungkan pada sisa pakan yang diberikan untuk ikan mas. Pada penelitian ikan mandiri, pasokan pakan diberikan secara teratur berdasarkan bobot ikan per hari. Nilai sintasan dari benih unggul setara dengan nilai sintasan benih dari Nirwana 2 yang mempunyai nilai 75\%-85\% (Dinas Kelautan dan Perikanan Provinsi Jawa Barat, 2011). Hal ini dapat dipahami mengingat salah satu induk pembentuk nila unggul adalah dari jenis induk nila Nirwana.

Tabel 1. Sintasan (\%) benih asal pemuliaan dan lokal selama periode pembesaran Table 1. Survival rate (\%) of "good quality" and local seed for grow out period

\begin{tabular}{ccc}
\hline $\begin{array}{c}\text { Ulangan } \\
\text { Replication }\end{array}$ & $\begin{array}{c}\text { Nila unggul } \\
\text { “Good quality” seed }\end{array}$ & $\begin{array}{c}\text { Nila lokal } \\
\text { Local seed }\end{array}$ \\
\hline 1 & 70.30 & 48.53 \\
2 & 84.11 & 40.82 \\
3 & 63.18 & 88.85 \\
4 & 65.36 & 50.91 \\
\hline Rataan (Average) & 70.74 & 57.28 \\
Sd (Standard deviation) & 9.40 & 21.50 \\
\hline
\end{tabular}


Lebih jauh, hasil kegiatan pemuliaan ikan nila ini juga dapat dilihat pada standar deviasi yang dihasilkan. Benih unggul mempunyai nilai standar deviasi yang lebih kecil dibandingkan dengan benih ikan lokal. Jika dihitung koefisien variasi (CV) maka benih nila unggul mempunyai besaran nila $C V=13,29 \%$ sedangkan benih ikan nila lokal mempunyai nilai CV $=37,53 \%$. Keadaan ini mengindikasikan bahwa kegiatan seleksi yang dilakukan secara tidak langsung ada kaitannya dengan sintasan, walaupun tujuan seleksi pada ikan nila yang digunakan pada penelitian ini adalah pertumbuhan.

Berdasarkan Tave (1986), menyatakan bahwa variasi ikan nila unggul yang digunakan pada penelitian ini mempunyai nilai variasi yang kecil kaitanya dengan sintasan. Dengan demikian pada kegiatan pemuliaan berikutnya untuk meningkatkan sintasan dari ikan nila yang dipelihara secara jaring ganda sebaiknya tidak menggunakan seleksi karena akan mempunyai efek pengaruh seleksi yang kecil pada sintasan.

\section{Pertambahan Bobot Total Harian}

Secara statistik terdapat perbedaan yang nyata pada pertambahan bobot total harian nila unggul dan lokal $(P<0,05)$. Benih nila unggul mempunyai pertambahan bobot harian yang lebih baik dibandingkan dengan benih ikan nila lokal. Tercatat bahwa nila unggul mempunyai pertambahan bobot total harian antara 4,92-8,92 kg sedangkan benih lokal mempunyai pertambahan bobot total harian 0,91-5,34 kg (Tabel 2).

Jika dibandingkan dengan nilai pertambahan bobot relatif pada pembesaran ikan nila dengan sistem mandiri yang telah diuji coba di Waduk Jatiluhur dan Cirata, maka pertambahan bobot nila unggul dan lokal ini lebih rendah. Pertambahan bobot total harian pada penelitian ini hanya setara dengan 1,64\%-2,97\% sedangkan pertambahan bobot relatif harian ikan nila di Jatiluhur dan Cirata secara mandiri adalah 11,21\% (Cirata) dan 12,96\% (Jatiluhur) (Nugroho, 2012a). Pemberian pakan secara teratur diduga menjadi salah satu penyebab perbedaan antara pemeliharaan secara jaring ganda dan mandiri. Hal serupa juga terjadi pada budidaya nila dengan KJA di Lake Taal, Filipina yaitu budidaya nila yang hanya mengandalkan pakan alami, diperlukan waktu 6 bulan dari ukuran $10 \mathrm{~g}$ untuk menjadi $200 \mathrm{~g}$, sedangkan ikan nila yang diberi pakan pelet dapat mencapai ukuran yang sama dalam waktu 4 bulan (Eguia \& Eguia, 2004).

Efek dari kegiatan pemuliaan juga tercermin pada pertambahan total bobot harian. Benih unggul mempunyai nilai standar deviasi yang lebih kecil dibandingkan dengan benih ikan lokal terhadap pertambahan bobot total harian. Jika dihitung koefisien variasi (CV) maka benih nila unggul mempunyai besaran nilai $\mathrm{CV}=23,55 \%$ sedangkan benih ikan nila lokal mempunyai nilai CV $=55,07 \%$. Keadaan ini mengindikasikan bahwa kegiatan seleksi yang dilakukan mempunyai kaitan secara langsung dengan pertambahan bobot total harian.

Dibandingkan dengan parameter sintasan, maka pada kegiatan seleksi keterkaitannya dengan pertambahan bobot total harian sebagai perwujudan dari pertumbuhan yang merupakan tujuan dari kegiatan seleksi ikan nila masih mempunyai peluang untuk berhasil. $\mathrm{Hal}$ ini tergambar dari nilai CV dari pertambahan bobot total harian yang lebih besar dari

Tabel 2. Pertambahan total bobot harian $(\mathrm{kg} / \mathrm{hari})$ dari benih hasil pemuliaan dan lokal

Table 2. Daily weight total addition ( $\mathrm{kg} /$ day) of "good quality" and local seeds

\begin{tabular}{ccc}
\hline $\begin{array}{c}\text { Ulangan } \\
\text { Replication }\end{array}$ & $\begin{array}{c}\text { Nila unggul } \\
\text { “Good quality" seed }\end{array}$ & $\begin{array}{c}\text { Nila lokal } \\
\text { Local seed }\end{array}$ \\
\hline 1 & 7.35 & 3.95 \\
2 & 7.69 & 3.58 \\
3 & 4.92 & 5.34 \\
4 & 8.92 & 0.91 \\
\hline Rataan (Average) & 7.22 & 3.45 \\
Sd (Standard deviation) & 1.70 & 1.90 \\
\hline
\end{tabular}


CV sintasan. Pelaksanaan seleksi pada populasi dengan nilai CV yang lebih besar akan lebih terlihat efeknya dibandingkan populasi dengan nilai CV yang lebih kecil (Tave, 1986). Sebagai implikasinya, varietas yang sudah dirilis ini masih dapat diperbaiki pertumbuhannya dengan melakukan program seleksi lebih lanjut agar diperoleh keberhasilan yang baik.

\section{Produksi Total (Panen Total)}

Secara statistik terdapat perbedaan yang nyata antara produksi total dengan menggunakan benih unggul dan benih lokal $(P<0,05)$. Dengan kontribusi sintasan dan pertambahan bobot total harian yang lebih baik maka dapat dipahami bahwa benih nila unggul mempunyai nilai produksi total atau panen total yang lebih tinggi pula dibandingkan benih ikan nila lokal. Hal ini tertera pada Tabel 3, produksi total dari benih nila unggul berkisar antara $834-1408 \mathrm{~kg}$ sedangkan benih nila lokal mempunyai total produksi berkisar antara $392-821 \mathrm{~kg}$.

Terlihat bahwa benih ikan unggul mempunyai kemampuan produktivitas sekitar 2 kali lipat dibandingkan dengan benih ikan lokal. Keadaan ini sesuai dengan hasil dari pengujian di laboratorium pada ikan nila BEST (Bogor) yang mempunyai pertumbuhan hingga 200\% dibandingkan ikan kontrol (Gustiano, 2009).

Koefisien variasi pada produksi total antara kedua perlakuan relatif seimbang. Tercatat benih nila unggul dan lokal masing-masing mempunyai nilai CV $=28,74 \%$ dan $28,38 \%$. Tingkat produksi yang diperoleh pada penelitian ini berada di atas hasil pemeliharaan ikan secara mandiri. Namun demikian, waktu yang dibutuhkan untuk mencapai ukuran konsumsi relatif lebih lama dibandingkan ikan nila yang diberikan pakan secara mandiri. Nugroho (2012a) memerlukan waktu 70 hari untuk mendapatkan ukuran konsumsi, namun budidaya ikan nila dengan sistem jaring ganda memerlukan waktu antara 90-135 hari.

\section{Nilai Ekonomi}

Nilai ekonomi atau laba yang didapatkan berkaitan erat dengan harga pokok produksi (HPP) per kilogram daging ikan nila. HPP ini berhubungan langsung dengan keberlanjutan usaha dalam budidaya perikanan. Pembudidaya akan mencari alternatif teknologi sistem budidaya ikan agar mendapatkan HPP ikan yang diproduksi serendah mungkin, sehingga masih tersisa margin keuntungan yang cukup dalam usaha budidaya ikan. Jika margin hanya sedikit maka alternatif lainnya adalah mendongkrak jumlah produksi budidaya setinggi mungkin sehingga total marginnya pun akan meningkat.

Budidaya jaring ganda dengan menggunakan benih unggul ternyata menghasilkan keuntungan sekitar 4 kali daripada budidaya dengan menggunakan benih nila lokal. Tercatat keuntungan dengan menggunakan benih nila unggul rata-rata adalah $\mathrm{Rp}$ 7.305.000,-/unit jaring ganda dalam satu periode pemeliharaan, sedangkan jika menggunakan benih lokal maka keuntungan akan berkurang, dengan rata-rata nilai keuntungan $=\operatorname{Rp} 1.583 .310,-/$ unit jaring ganda dalam satu periode (Tabel 4). Melihat tingginya kelebihan margin yang dicapai dengan menggunakan

Tabel 3. Produksi total $(\mathrm{kg})$ ikan nila hasil pembesaran di KJA dari benih pemuliaan dan lokal

Table 3. Total production ( $\mathrm{kg}$ ) of tilapia grow up on net cages using selection and local seeds

\begin{tabular}{ccc}
\hline $\begin{array}{c}\text { Ulangan } \\
\text { Replication }\end{array}$ & $\begin{array}{c}\text { Nila unggul } \\
\text { “Good quality” seed }\end{array}$ & $\begin{array}{c}\text { Nila lokal } \\
\text { Local seed }\end{array}$ \\
\hline 1 & 1,160 & 624 \\
2 & 1,408 & 645 \\
3 & 834 & 821 \\
4 & 1,696 & 392 \\
\hline Rataan (Average) & $1,274.50$ & 620.50 \\
Sd (Standard deviation) & 366.30 & 176.10 \\
\hline
\end{tabular}


Tabel 4. Nilai keuntungan dari budidaya dengan benih hasil pemuliaan dan lokal

Table 4. Benefit value of tilapia culture using "good quality" and local seeds

NILA UNGGUL (GOOD QUALITY TILAPIA)

\begin{tabular}{ccccccc}
\hline & \multicolumn{7}{c}{ Biaya pengeluaran (Expenses) (Rp) } & Pendapatan \\
\cline { 2 - 7 } $\begin{array}{c}\text { Ulangan } \\
\text { Replication }\end{array}$ & $\begin{array}{c}\text { Ikan } \\
\text { Fish }\end{array}$ & $\begin{array}{c}\text { Penyusutan } \\
\text { Depreciation }\end{array}$ & $\begin{array}{c}\text { Sumberdaya } \\
\text { manusia } \\
\text { Inp) }\end{array}$ & $\begin{array}{c}\text { Profit } \\
\text { (Rp) }\end{array}$ \\
\hline 1 & $5,100,000$ & 100,000 & 150,000 & $5,350,000$ & $14,940,000$ & $9,590,000$ \\
2 & $5,100,000$ & 100,000 & 150,000 & $5,350,000$ & $12,672,000$ & $7,322,000$ \\
3 & $5,236,000$ & 100,000 & 150,000 & $5,486,000$ & $7,506,000$ & $2,020,000$ \\
4 & $4,726,000$ & 100,000 & 150,000 & $4,976,000$ & $15,264,000$ & $10,288,000$ \\
\hline $\begin{array}{l}\text { Rataan } \\
\text { Average }\end{array}$ & $5,040,000$ & 100,000 & 150,000 & $5,290,000$ & $12,595,000$ & $7,305,000$ \\
$\begin{array}{l}\text { Sd (Standard } \\
\text { deviation) }\end{array}$ & 219.249 & - & - & 219.249 & $3,583,594$ & $3,743,930$ \\
\hline
\end{tabular}

NILA LOKAL ( LOCAL TILAPIA)

\begin{tabular}{|c|c|c|c|c|c|c|}
\hline \multirow[b]{2}{*}{$\begin{array}{c}\text { Ulangan } \\
\text { Replication }\end{array}$} & \multicolumn{4}{|c|}{ Biaya pengeluaran (Expenses) $(\mathrm{Rp})$} & \multirow{2}{*}{$\begin{array}{l}\text { Pendapatan } \\
\text { Income } \\
\text { (Rp) }\end{array}$} & \multirow{2}{*}{$\begin{array}{c}\text { Keunt ungan } \\
\text { Profit } \\
\text { (Rp) }\end{array}$} \\
\hline & $\begin{array}{l}\text { Ikan } \\
\text { Fish }\end{array}$ & $\begin{array}{l}\text { Penyusut an } \\
\text { Depreciation }\end{array}$ & $\begin{array}{c}\text { Sumberdaya } \\
\text { manusia } \\
\text { Manpower }\end{array}$ & Total & & \\
\hline 1 & $5,100,000$ & 100,000 & 150,000 & $5,350,000$ & $5,616,000$ & 266,000 \\
\hline 2 & $5,372,000$ & 100,000 & 150,000 & $5,622,000$ & $5,805,000$ & 183,000 \\
\hline 3 & $5,236,000$ & 100,000 & 150,000 & $5,486,000$ & $7,389,000$ & $1,903,000$ \\
\hline 4 & $5,236,000$ & 100,000 & 150,000 & $5,486,000$ & $3,528,000$ & $(1,958,000)$ \\
\hline $\begin{array}{l}\text { Rataan } \\
\text { Average }\end{array}$ & $5,236,000$ & 100,000 & 150,000 & $5,486,000$ & $5,584,500$ & 98,500 \\
\hline $\begin{array}{l}\text { Sd (Standard } \\
\text { deviation) }\end{array}$ & 111.044 & - & - & 111.044 & $1,584,826$ & $1,583,310$ \\
\hline
\end{tabular}

benih unggul ini semakin menambah keyakinan bahwa benih unggul menjadi salah satu kunci keberhasilan suatu budidaya ikan, khususnya ikan nila.

Hal serupa juga telah dilakukan oleh Cina dalam industrialisasi ikan nila. Penggunaan benih unggul ini merupakan salah satu pilar dari industrialisasi ikan nila yang sukses dilaksanakan oleh pemerintah Cina sejak tahun 1992, sehingga saat ini Cina dikenal sebagai negara produsen utama ikan nila. Tercatat produksi ikan tilapia di Cina telah mencapai sekitar 1,2 juta ton atau senilai US\$1,3 miliar pada tahun 2002 (Xinhua et al., 2011).

\section{KESIMPULAN}

Penggunaan benih unggul hasil kegiatan pemuliaan dapat meningkatkan produktivitas hingga 2 kali dari budidaya ikan nila yang menggunakan benih lokal. Keuntungan meningkat hingga 4 kali jika menggunakan benih unggul dibandingkan dengan penggunaan benih lokal.

\section{DAFTAR ACUAN}

Dinas Kelautan dan Perikanan Provinsi Jawa Barat. 2011 . Naskah permohonan pelepasan varietas Nirwana II (Orechromis niloticus). 
Effendie, M.I. 1979. Metode biologi perikanan. Yayasan Dewi Sri, Bogor.

Eguia, R.V. \& Eguia, M.R.R. 2004. Tilapia Farming in Cages and Ponds. SEAFDEC Aquaculture Department. Tigbauan, Iloilo, Philippines, $40 \mathrm{pp}$.

Gustiano, R. 2009. Dokumen rilies varietas unggul nila BEST. Balai Riset Perikanan Budidaya Air Tawar, Bogor.

Nugroho, E. 2012a. Kajian lapang budidaya keramba jaring apung ikan nila "mandiri" di Waduk Cirata dan Jatiluhur. Media Akuakultur, 6(1): 54-58.

Nugroho, E. 2012b. Budidaya nila unggul dongkrak keuntungan. Trobos, 150(XIII) bulan Maret.
National Research Council. 1983. Nutrient Requirement of Warmwater Fishes. National Academy of Sciences. Washington D.C., 71 pp.

Norman, H.N., Bent, D.H., \& Hule, C.H. 2010. Software SSPS Version 16.

Tave, D. 1986. Genetics for Fish Hatchery Managers. AVI Publishing Company, Inc. Westport, Connecticut, 299 pp.

Xinhua, Y., Pao, X., Zaijie, D., Wei, Y., \& Xiaojun, J. 2011 . Training Course on Tilapia Seed Production for Indonesia SAFVER Project. Freshwater Fisheries Research Center, Wuxi, China, 63 pp. 